\title{
Interactive Online Advertising: The Effectiveness of Marketing Strategy towards Customers Purchase Decision
}

\author{
Nurul Zarirah Nizam ${ }^{1, *}$, Johanna Abdullah Jaafar ${ }^{2}$, and Siti Hindun Supaat ${ }^{3}$ \\ ${ }^{12}$ Faculty of Technology Management \& Technopreneurship, Universiti Teknikal Malaysia Melaka, Malaysia \\ ${ }^{3}$ Centre of Graduate Studies, Universiti Teknikal Malaysia Melaka, Malaysia
}

\begin{abstract}
A growing of IT industry made many companies used Internet as their mediators on advertising platform to control over the promotion materials and it possess greater reliability and flexibility. Internet also becoming an important stop point for customers in finding their needs and wants. This study has been designed to measures how significant is the online advertising effectiveness in terms of attitude towards ads, ability to recall ads and frequency of clicking ads in explaining purchase decision in Malacca, Malaysia. A series of survey was conducted from 200 respondents and were analyzed quantatively. The results showed among the attitude towards ads, ability to recall and frequency of clicking ads had significantly gave impact to the purchasing decision by the customers. For the recommendations discussed to the advertisers to have good understanding on how to advertise effectively (using marketing strategy program) and do some innovation of the products in terms of the products association.
\end{abstract}

\section{Introduction}

Online advertising is widely used by companies and organization to promote their product and services. The reason is, online advertising able to capture the opportunity to reach their consumers via various online platforms to create an awareness for their products to lead their sales in future [2]. Online advertising as a form of promotion that uses the internet and worldwide web to deliver marketing messages to attract customers. Example of online advertising according to Wikipedia, include contextual ads on search engine results pages, banner ads, blogs, rich media ads, special networking advertising, interstitial ads, online classified advertising, advertising networks and e-mail marketing, including email spam. Many of these types of ads are delivered by an ad server. The view that "rapid growth in online advertising revenues indicates the viability of worldwide web advertising as an alternative to that of traditional media considering internet advertising growth, there is little doubt that the internet is a powerful and viable alternative to traditional media advertising" [1]. On the other hand, online advertising is flexible and makes it easier for the company to update their products, information [4]. Due to the diversity of products and services, increasing customers' desire and demand, producers need to be faster and more efficient method to reach the consumer loyalty [28]. Consumers' attitude is direct human reflection towards the online advertising. The attitude of consumers may be influenced by the factors of online advertising, such as in formativeness, entertainments, creates awareness and annoying. For example, the internet users might found online advertising was informative but less entertaining and it did not encourage them to make purchases even they did not perceive it to increase product prices [12]. In this new medium, consumers have control over the advertising exposure as they can choose when and how much advertisement content they wish to view. Consumers will immediately terminate the visit if they find that the web advertisement is not useful [1]. In addition, consumers behavior on online advertising may evolve from time to time [8] thus there are still lack of understanding and information on how consumers react to online advertising in Malaysia [2].

\subsection{Online Advertising}

The effectiveness of online advertising in purchase decision and concluded that Malaysian consumers are quite receptive to online advertising with a positive attitude towards online advertising [12]. This study is to target the marketers and advertisers on the consumer preference of the advertising media and to determine whether using online advertising would be effective in reaching and creating awareness among the target audience. Internet has grown in recognition as an advertising platform because it allows 24 hours interactivity between the advertiser and the consumer. As more consumers has turn to the internet as their purchasing platform, it is important for the local

* Corresponding author: zarirah@utem.edu.my 
businesses to look into internet advertising. A small enterprise that can offer online purchasing may be gain advantages among the competitors. Thus, it is imperative for the organizations to understand the characteristics of the online customers towards online advertising before adapting this new marketing practices. Other the other hand, the government sector would understand the value of internet advertising and its influence on consumer behaviors from this study. In addition, the government can effectively regulate how internet advertising is delivered among the consumers by acting rationally on laws that could restrict data usage and at the same time protecting the consumers' interest and rights. For scholars and academic researchers, the study will act as a reference for future research on internet advertising. The findings of this study can be resourceful in providing viable information to the researchers and consumers in the future.

\subsection{Effectiveness of Online Advertising}

Several effectiveness indicators of advertising on the Internet have been developed specifically to measure the persuasive power of this form of communication [15]. Previous academic studies incorporates a vast spectrum of studies on internet advertising effectiveness measured via direct response and branding metrics [22]. Internet advertising is a fairly new medium which has acquired large attention from academics and practitioners. The study of online advertising effectiveness has been carried out through two alternative paradigms. The primary, broadly used in academic research, argues that internet advertisement should be considered as a form of marketing communication used to elevate brand awareness. The second one, predominantly used in empirical studies, contends that the internet is a direct marketing medium, and subsequently a banner ad is likened to a coupon in print media [22]. Numerous studies have examined the effectiveness of Online advertising in the past decade [12]. There are few types of these common measures, attitudes toward the ad, ability to recall ad and clicks on ad, are the focus of the present study. The effectiveness of these three measures was assessed by their ability to predict online purchase decision [12].

\subsubsection{Attitudes towards Online Ads}

Attitude is a fairly global and enduring evaluation of an object, issue, person or action [6]. In other words, it could be described as an overall evaluation that expresses the extent of favor or disfavor of a person towards an object, issue, person, or action and it tends to be a long lasting emotional feeling. While the multiattribute attitude model such as the Fishbein model is the most influential model and assumes that a consumer's attitude of an object will rely upon the beliefs she or he has about numerous or many attributes of the object [2]. Malaysia internet users or consumers are aware of advertising and they have a positive and negative perception of web advertising. From the study, they concluded that they still formed positive beliefs on web advertising such as for retrieving up-to-date information about products available in the marketplace and web advertising is a convenient source of good information [1]. On the study of assessing beliefs, attitudes, and behavioral responses toward online advertising in three countries: the five common belief factors, entertainment, information, credibility, economy and value corruption were significant predictors of attitudes towards online advertising [16] [17].

\subsubsection{Ability to Recall Online Ads}

There are a lot of researchers have studied numerous factors that might have an impact on online advertising recall [12]. These factors such as ad characteristics, internet users' viewing mode, and time spent on viewing and so on. Consumer able to recall the advertisement because of its necessity and usefulness of the ads. Other than that, prices of the product displayed online also influence the customer to recall the advertisement [4]. Furthermore, previous study additionally suggests that there has been a close association between animated advertisement and banner simple text followed by floating advertisement pop up advertisement and embedded video. It is also significant to note that online advertisement is taken into consideration that is important to majority of the respondents are of the opinion that they recall the product through seeing the advertising of the product online [4]. The effects and effectiveness of interactive advertising and found that traditional measures of advertising effectiveness, such as recall, attitude change, and brand choice are only a part of the story of effectiveness of interactive advertising [18]. However, such measures are useful, but they are in the tradition of advertising research that focused on the advertising's influence on the consumer. These measures offer limited insight into what the consumer does to and with advertising. Traditional measures such as awareness, recall, and attitude change and purchase behavior are also relevant in an interactive advertising context [18].

\subsubsection{Frequency of Clicking Online Ads}

A click-through rate (CTR) is a measure of online advertising effectiveness have examined the relationships between CTR and a series of factors such as web user motives, audience targeting, exposure frequency, copy content and a limited number of design elements of banner ads [22]. Several studies suggest that click-through effectiveness may depend on web user motives. Click-through rates provide the marketer with considerable advantages, as click-through record voluntary behavior in the actual medium environment [22]. On the study of internet advertising effectiveness: the effect of design on click-through rates for banner ads, the largest banner ads are more effective in generating 
click-through than the smaller-sized banners [22]. The author also suggested that unbranded banners stimulate greater curiosity, hence generating more clicks. On the study of the effectiveness of internet advertising through memorization and click on a banner, found that clickthrough rate is an operation technically easier to achieve in the sense that we can easily know the number of times the webpage is loaded and the number of times one has clicked on the banner [15].

\section{Method}

Quantitative method was used in this study and research was conducted through the use of questionnaire. The survey was conducted in Malacca and a total of 200 questionnaires has distributed to the target population. The target population was the consumers who live in Malacca City and their age range is between 19 to 26 years old. In this study, descriptive analysis was used to describe targeted respondent demographic by using frequency and percentage. Another analysis was Pearson Product Moment Correlation Coefficient (PMCC) used to assess the strength of relationship between the two variables as presented in Table 3.

\section{Analysis and Result}

Table 1. Descriptive Analysis of Respondents Demographic Profile

\begin{tabular}{|c|c|c|c|}
\hline & & Frequency & Percentage \\
\hline \multirow[t]{2}{*}{ Gender } & \multirow{2}{*}{$\begin{array}{l}\text { Male } \\
\text { Female }\end{array}$} & 100 & 51 \\
\hline & & 96 & 49 \\
\hline \multirow[t]{4}{*}{ Age } & \multirow{4}{*}{$\begin{array}{l}20 \text { and below } \\
21-30 \\
31-40 \\
41 \text { and above }\end{array}$} & 10 & 5.1 \\
\hline & & 103 & 52.6 \\
\hline & & 72 & 36.7 \\
\hline & & 11 & 5.6 \\
\hline \multirow[t]{2}{*}{ Marital Status } & \multirow{2}{*}{$\begin{array}{l}\text { Single } \\
\text { Married }\end{array}$} & 118 & 60.2 \\
\hline & & 78 & 39.8 \\
\hline \multirow{5}{*}{$\begin{array}{l}\text { Education } \\
\text { Level }\end{array}$} & \multirow{5}{*}{$\begin{array}{l}\text { SPM } \\
\text { STPM/DIP/A- } \\
\text { levels } \\
\text { Bachelor's } \\
\text { Degree } \\
\text { Master } \\
\mathrm{PhD}\end{array}$} & 40 & 20.4 \\
\hline & & 38 & 19.4 \\
\hline & & 94 & 48 \\
\hline & & 19 & 9.7 \\
\hline & & 5 & 2.6 \\
\hline \multirow{3}{*}{$\begin{array}{l}\text { Employment } \\
\text { Status }\end{array}$} & Student & 65 & 33.2 \\
\hline & $\begin{array}{l}\text { Employment/ } \\
\text { Self-employed }\end{array}$ & 112 & 57.1 \\
\hline & $\begin{array}{l}\text { Unemployed/Ho } \\
\text { usewife }\end{array}$ & 19 & 9.7 \\
\hline Monthly & 1000 and below & 81 & 41.3 \\
\hline
\end{tabular}

\begin{tabular}{|l|l|l|l|}
\hline Salary (RM) & $1001-2000$ & 29 & 14.8 \\
\cline { 2 - 4 } & $2001-3000$ & 35 & 17.9 \\
\cline { 2 - 4 } & $3001-4000$ & 30 & 15.3 \\
\cline { 2 - 4 } & 4001 and above & 21 & 10.7 \\
\hline
\end{tabular}

The background of the respondent is important in conducting research. This is because the respondent contributed to the value of the research as well. The general information of the respondents which involved the gender, age, employment status and monthly salary (refer Table 1). The number of male respondents is more than female which represent 100 person (51.02\%) and 96 person $(48.98 \%)$ of each. Specifically, based on Table 1 we can see, gender: Male contribute more with $51 \%$, Age: within $21-30$ years old represent $52.6 \%$, marital status: single person with $60.2 \%$, educational level: bachelor's degree with $48 \%$, employment status: employment/self-employed contribute $57.1 \%$ and monthly salary: 1000 and below with $41.3 \%$ which represent dominant in every level of demographic.

Table 2. Frequency click on online advertisement by respondents

\begin{tabular}{|c|c|c|c|c|}
\hline & & Frequency & Percent & $\begin{array}{l}\text { Valid } \\
\text { Percent }\end{array}$ \\
\hline \multirow{4}{*}{ Valid } & Click at least once & 48 & 24.5 & 24.5 \\
\hline & Occasionally click & 88 & 44.9 & 44.9 \\
\hline & Frequently click & 60 & 30.6 & 30.6 \\
\hline & Total & 196 & 100.0 & 100.0 \\
\hline
\end{tabular}

From the total of 196 respondents, 59 (30.1\%) people averagely spend between $16-25$ hours per week online. The second highest is between $26-35$ hours with 58 $(29.59 \%)$ people. There are $38(19.39 \%)$ people average spend between $6-15$ hours per week online, followed by $25(12.76 \%)$ people average spend 5 hours and below online. Lastly, there are least $16(8.16 \%)$ people send 35 hours and above per week online as showed in Table 2.

Table 3. Pearson's Product Moment Correlation Coefficient (PMCC)

\begin{tabular}{|c|c|c|c|c|}
\hline & 1 & 2 & 3 & 4 \\
\hline $\begin{array}{l}\text { 1.Attitude } \\
\text { towards ads }\end{array}$ & 1 & & & \\
\hline $\begin{array}{l}\text { 2.Ability to recall } \\
\text { ads }\end{array}$ & $.700 *$ & 1 & & \\
\hline $\begin{array}{l}\text { 3.Frequency of } \\
\text { clicking ads }\end{array}$ & $.847 * *$ & $.763 * *$ & 1 & \\
\hline $\begin{array}{l}\text { 4.Purchase } \\
\text { decision }\end{array}$ & $.778 * *$ & $.745^{* *}$ & $.821 * *$ & 1 \\
\hline
\end{tabular}

Note: $\mathrm{N}=196^{* *}$ Correlation is significant at the 0.01 level (2tailed). 
Table 3 stated that the $p$-value (sig.) of the correlation between independent variables (attitude towards ads, ability to recall ads and frequency of clicking ads) and the dependent variable (purchase decision) is less than 0.01 . This reflects that there is a significant relationship between them. The positive value of correlation coefficient indicated that the relationships between each independent variables and dependent variable are positively related. The strength of the relationships is strong as all the values of correlation coefficient are greater than 0.7 .

Among all the independent variables, the strength of association between attitude towards ads and frequency of clicking ads are the strongest $(\mathrm{r}=0.847)$, and the correlation coefficient is highly significant $(p=0.000)$. This explained that the attitude towards ads have a positive and strong relationship with the frequency of clicking ads.

Conversely, the strength of association between attitude towards ads and ability to recall ads is the weakest among all the independent variables $(\mathrm{r}=0.700)$. This shows that there is a moderate relationship between the two variables.

On the other hand, the $p$-value (sig.) of the correlation between independent variables (attitude towards ads, ability to recall ads and frequency of clicking online ads) and the dependent variable (purchase decision) is 0.000 which is less than 0.01 . This reflects that there is a significant relationship between them. The value of correlation coefficient of frequency of clicking ads and purchase decision is 0.821 , which indicated that there is a strong positive relationship between this two variable. Followed by attitude towards ads and purchase decision with the value of 0.778 and lastly the ability to recall ads and purchase decision with the value of 0.745 .

\subsection{Multiple Linear Regression}

Table 4. R square

\begin{tabular}{|c|c|c|c|c|}
\hline Model & R & R Square & $\begin{array}{l}\text { Adjusted } \\
\text { R Square }\end{array}$ & Std. Error of the Estimate \\
\hline 1 & $.851^{\mathrm{a}}$ & .724 & .720 & .29685 \\
\hline
\end{tabular}

a. Predictors: (Constant), Frequency of Clicking ads, Ability to Recall ads, Attitude toward ads

Table 5. Coefficients

\begin{tabular}{|l|l|l|l|}
\hline & Beta & $\mathrm{t}$ & Sig. \\
\hline $\begin{array}{l}\text { Attitude } \\
\text { toward ads }\end{array}$ & .244 & 3.387 & .001 \\
\hline $\begin{array}{l}\text { Ability to } \\
\text { Recall ads }\end{array}$ & .252 & 4.240 & .000 \\
\hline $\begin{array}{l}\text { Frequency of } \\
\text { Clicking ads }\end{array}$ & .422 & 5.296 & .000 \\
\hline
\end{tabular}

a. Dependent Variable: Purchase Decision
Regression analysis is used to find the relationship between the two variables. Regression analysis can also be used to predict the values of a dependent variable given the values of one or more independent variables by calculating a regression equation.

Table 5 reported that ANOVA ${ }^{\text {a }}$ shows that the F-ratio value of 167.873 with a significance level of $0.000^{\mathrm{b}}(p-$ value $=0.000$ ), which is below 0.01 . This indicated that there is a statistically significant difference between the dependent variable (purchase decision) and independent variable (attitude toward ads, ability to recall ads and frequency of clicking ads). Therefore, the overall model is significance.

Standardize coefficients (Beta) among the independents variables ranged from the weakest relationship of 0.244 (between attitude toward ads and purchase decision) to the strongest relationship of 0.422 (between frequency of clicking online ads and purchase decision). Therefore, this shows that the frequency of clicking online ads has the strongest effect on consumer online purchase decision. Whereas, attitude toward ads has the lesser impact on the purchase decision. While ability to recall ads ranked as the second important independent variable with the coefficient of 0.252 .

\section{Conclusion}

\subsection{Attitude towards online ads is significantly related to purchase decision.}

Referring to Table 6 , from the 3 independent variables, attitude towards online advertising has the weakest effect on purchase decision. The beta value of attitude towards online advertising is 0.244 with 0.000 significant value. This indicated that there is a significant relationship between attitude towards online advertising and purchase decision. Attitudes are primarily based on the cognitions or beliefs which mean attitudes can be formed based on thoughts and beliefs we've about the information received [6]. In other words, consumers who believes the information of the product or services will have favorable attitude and purchase intention. When a person wants to purchase a product or services, he or she will make decision based on the available information and also based on the belief of the individual towards the product or services. Attitude towards a product or brand can be anticipated by figuring out these specific beliefs and mixing them to derive a degree of the consumer's overall attitude [1]. Exploring consumers' attitude towards web advertising and its influence on web ad usage in Malaysia [2]. Malaysia internet users or consumers are aware of advertising and they have a positive and negative perception of web advertising [2]. From the study, they concluded that they still formed positive beliefs on web advertising such as for retrieving up-to-date information about products available in the marketplace and web advertising is a convenient source of good information. Besides, individuals can make 
behavioral decisions via careful consideration of the available information [9]. In other words, purchase decision can be influenced by the available information which based on the attitude of the consumer towards the product or services.

\subsection{Ability to recall online ads is significantly related to purchase decision.}

Ability to recall online ads has the second strongest effect on purchase decision. The beta value of ability to recall online ads is 0.252 with 0.000 significant values which indicated that there is a significant relationship between ability to recall online ads and purchase decision. Means that, the consumers that have higher ability to recall the ads will most likely purchase the product or services. This is because the consumer spent more time and repeatedly view on the advertisement. There are a lot of researchers have studied numerous factors that might have an impact on online advertising recall [12]. These factors such as ad characteristics, internet users' viewing mode, and time spent on viewing and so on.

\subsection{Frequency of clicking online ads is significantly related to purchase decision.}

For frequency of clicking online ads has the strongest effect on purchase decision, the beta value of frequency of clicking online ads is 0.422 with 0.000 significant values. This indicated that there is a significant relationship between frequency of clicking online ads and purchase decision. This result shows that consumer with higher frequency of clicking on the advertisement will have chances to purchase the product or services. A click-through rate is a measure of online advertising effectiveness and it record the voluntary behavior in the actual medium environment [21]. The author found that the largest banner ads are more effective in generating click-through than the smaller-sized banners. The author also suggested that unbranded banners stimulate greater curiosity, hence generating more clicks. In other words, sizes of the banner and curiosity will influence the clicks from the consumer. When the consumers click on the advertisement, it will more likely generate the positive impact on the consumer to purchase the product or services. This is supported by the study [11]. Advertisement that appear to be interesting and attractive to create consumers' curiosity and draw their attention, they may click on the advertisement [11]. Consumer will click on the advertisement if they appear to be interesting and stimulating visually when they are doing aimless browsing for something interesting, which may lead to impulse buying [11]. Besides that, a potential barrier to advertising effectiveness is the quantity of ads to which consumers are exposed, which it indicate that online ad position can also play a position in attracting visitors [23]. This causes the interactive rich media ad earned a substantially higher average daily click-through rate.

Nowadays, almost everyone has Internet access in their life due to the technology advancement. Therefore, with the increasing importance of internet in ecommerce, advertisers should fully utilize this online platform for their advertising activities that fulfill their communication purposes with consumers. The purpose of the study was to measure the effectiveness of online advertising on consume behavior in Melaka. According to the literature review, attitude towards ads, ability to recall ads and frequency of clicking ads was the determinants of consumer behavior. The result has indicated that each variable has significant relationship with the purchase decision. Based on the result, frequency of clicking ads with beta value of 0.422 has the strongest impact on purchase decision. In other words, frequency of clicking ads was the most significant determinant that influence purchase decision. This is because when consumer click on advertisement that draws their attention, it will more likely lead them to purchase the product or services. Lastly, from the results of the research, it has provided evidences to support that attitude toward ads, ability to recall ads and frequency of clicking ads are important measurement tools for company or marketer to take into consideration for them to improve their advertising skills. By understanding all the important elements in online advertising, marketer can create a better and effective advertisement to draw attention from consumers.

\section{Conclusion and Future Work}

For the future research, future researchers are recommended to broaden the research by incorporating a larger sample size of respondents. Sample are recommended to draw from different geographic area and the age of the respondents should also be taken into consideration when drawing the sample. Future researcher should cover the whole Malaysia to obtain a more accurate result. Most of the respondents in this research are young consumer, therefore, the future researchers can target as many as possible different age of consumer. Thus, the result can indicate the effectiveness of online advertising in each level of age. This can also generate a better and more accurate result. Furthermore, the future research questionnaire should be provided in dual languages such as Bahasa Malaysia or Mandarin in order to help the respondents who are poor in understanding English. This method may help the researcher to save time for explanation and enable to reach out to more respondents.

Last but not least, due to lack of information about online advertising causes difficulty for researcher to get information. Therefore, more research should be done in Malaysia. In addition, as technology going fast nowadays, research should not just focus on traditional advertising but also online advertising. This will be 
easier for future researchers to get information regarding this topic.

Thanks are expressed to Low Yong Jie for his help in collecting the data used in the study while fulfilling his role as an undergraduate student at the time.

\section{References}

1. Aziz, N., Yasin, N. \& Kadir, B., 2008. Web Advertising Beliefs and Attitude: Internet Users' View. The Business Review, Cambridge, 9(2), pp.332-339. Available at: http://abufara.com/abufara.net/images/abook_file/We b Advertising Beliefs and Attitude- Internet Users\%E2\%80\%99 View.pdf [Accessed November 25, 2016].

2. Baumeister, R.F. et al., 2008. Free will in consumer behavior: Self-control, ego depletion, and choice. 18, pp.4-13.

3. Busen, S.M.S., Mustaffa, C.S. \& Bahtiar, M., 2016. Impacts of online banner advertisement on consumers' " purchase intention: A theoretical framework., 3(1), pp.75-82.

4. Chaubey, D.S., Sharma, L.S. \& Pant, M., 2013. Measuring the Effectiveness of Online Advertisement in Recalling a Product: An Empirical Study. , pp.3747.

5. Hoyer, W. D. \& MacInnis, D. J., 2010. Consumer Behavior (5th Ed.). Boston: Cengage Learning.

6. Johnson, E. J., Pham, M. T. \& Johar, G. V., 2007. Consumer Behavior and Marketing. In: Social Psychology. Handbook of Basic Principles (2nd Ed.). New York: The Guildford Press, pp. 869-887.

7. Karson, E.J., McCloy, S.D. \& Bonner, P.G., 2006. An Examination of Consumers' Attitudes and Beliefs towards Web Site Advertising. Journal of Current Issues \& Research in Advertising, 28(2), pp.77-91. Available at: http://www.tandfonline.com/doi/abs/10.1080/106417 34.2006 .10505200 .

8. Kim, J.U., Kim, W.J. \& Park, S.C., 2010. Consumer perceptions on web advertisements and motivation factors to purchase in the online shopping. Computers in Human Behavior, 26(5), pp.12081222. Available at: http://dx.doi.org/10.1016/j.chb.2010.03.032.

9. Kotler, P. \& Amstrong, G., 2010. Principles of Marketing (13th Ed.). New York: Pearson.

10. Lee, S.M. \& Chen, L., 2016. The Impact of Flow on Online Consumer Behavior the Impact of Flow on Online Consumer Behavior University of NebraskaLincoln. , 4417(February).

11. Lim, Y., Yap, C. \& Lau, T., 2011. The Effectiveness of Online Advertising in Purchase Decision : Liking, Recall and Click. , 5(9), pp.1517-1524.

12. Mazaheri, E., Richard, M. \& Laroche, M., 2011. Online consumer behavior: Comparing Canadian and Chinese website visitors. Journal of Business
Research, 64(9), pp.958-965. Available at: http://dx.doi.org/10.1016/j.jbusres.2010.11.018.

13. Melissa, H., 2014. CMOs Are Preparing for Digital to Grow to $75 \%$ of Marketing Budgets. Available at: http://www.adweek.com/digital/cmos-expect-75marketing-budgets-be-digital-within-5-years158481/.

14. Nihel, Z., 2013. The Effectiveness of Internet Advertising through Memorization and Click on a Banner., 5(2), pp.93-101.

15. Nikhashemi, S.R., Paim, L. \& Sharifi, S., 2013. The Effectiveness of E-Advertisement towards Customer Purchase Intention: Malaysian Perspective. , 10(3), pp.93-104.

16. Nila, S.C.V., 2013. Consumer Attitude towards Internet Advertisement. , (March), pp.264-265.

17. Pavlou, P.A. \& Stewart, D.W., 2013. Measuring the Effects and Effectiveness of Interactive Advertising Advertising: A Research Agenda. (September 2014), pp.37-41.

18. Poddar, A., Donthu, N. \& Wei, Y., 2009. Web site customer orientations, Web site quality, and purchase intentions: The role of Web site personality. Journal of Business Research, 62(4), pp.441-450. Available at: http://dx.doi.org/10.1016/j.jbusres.2008.01.036.

19. Rani, P., 2014. Factors influencing consumer behaviour. , pp.52-61.

20. Razzouk, N. \& Seitz, V.A., 2008. Banner Advertising and Consumer Recall Banner Advertising and Consumer Recall : An Empirical Study. , 6491(June).

21. Robinson, H. et al., 2015. International Journal of Advertising: Internet advertising effectiveness Internet advertising effectiveness the effect of design on click-through rates., (January), pp.37-41.

22. Rosenkrans, G., 2013. The Creativeness and Effectiveness of Online Interactive Rich Media Advertising., (February 2015), pp.37-41.

23. Rosenkrans, G.L., 2006. Online banner ads and metrics challenges., 3(3), pp.193-218.

24. Rani, P., 2014. Factors influencing consumer behaviour., pp.52-61.

25. Robinson, H. et al., 2015. International Journal of Advertising: Internet advertising effectiveness Internet advertising effectiveness the effect of design on click-through rates. , (January), pp.37-41.

26. Wang, Y. \& Sun, S., 2010. Assessing beliefs, attitudes, and behavioral responses toward online advertising in three countries. International Business Review, 19(4), pp.333-344. Available at: http://dx.doi.org/10.1016/j.ibusrev.2010.01.004.

27. Zourikalatehsamad, Naser Payambarpour, S.A., Alwashali, I. \& Abdolkarimi, Z., 2015. The Impact of Online Advertising on Consumer Purchase Behavior Based on Malaysian Organizations. , 9(10), pp.33403345 . 